\title{
The others Compared to each other - Consequences for the Theory of Reciprocity
}

\author{
Jakub Dotlačil, Øystein Nilsen \\ Utrecht University, Utrecht University/University of Troms $\phi$
}

\section{Introduction}

Two markedly distinct analyses have been developed for reciprocal expression like each other. One very popular approach treats them as anaphoric noun phrases, i.e., noun phrases containing free variables that come with various constraints on their binding configurations. This approach, exemplified by (Heim et al. 1991a,b, Schwarzschild 1996, Sternefeld 1998, Beck 2001: a.o.), will be referred to as the anaphoric approach to reciprocals, or the A-approach for short. The other approach treats them as polyadic quantifiers (Keenan 1992, Dalrymple et al. 1998, Sabato and Winter 2005: a.o.). We refer to this as the polyadic quantifier approach, or simply the PQ approach.

Probably the most widely discussed problem connected to reciprocity is how to account for the variety of readings that reciprocal sentences can give rise to. Two of the different readings of reciprocal sentences are exemplified by the contrast in meaning between $(1 a, b)$. (1a) is true if both Burt and Clara like the other one among them, and false otherwise. (1b) seems to mean something weaker. In particular it doesn't require that both boxes are stacked on top of the other one.

(1) a. Burt and Clara like each other.

b. The two boxes are stacked on top of each other.

Dalrymple et al. (1998) provide a family of PQ-denotations for reciprocals, regulated by their Strongest Meaning Hypothesis (SMH). They argue that the resulting system can account for the full range of readings of reciprocal sentences. More recently, Sabato and Winter (2005) offer a PQ-analysis of reciprocals that achieves the same result with a single denotation by effectively building the SMH into the lexical meaning of each other. Sternefeld (1998) and Beck (2001) developed an approach to the problem of readings within an A-approach to reciprocals by attempting to reduce the variety of readings of reciprocal sentences to the readings obtained with regular plural sentences, viz. collective, distributive and cumulative construals (Langendoen 1977). Thus, we currently have two theories of reciprocals both of the variety of readings. One might then wonder whether there are other arguments that may force us to choose one theory over the other.

In this paper, we argue that both the A-approach and the PQ-approach are in fact neccessary but for different expressions. More in particular, we argue that

We are thankful to Gennaro Chierchia, Alexis Dimitriadis, Ora Matushansky, Rick Nouwen, and the audiences at TIN-dag 2008, GLOW XXXI and SALT XVIII. 
the PQ-approach is correct for each other, while the A-approach leads to an elegant account for the properties of the others. We present two arguments for this position. On the A-approach to reciprocals, the free variables that are postulated need to be bound by various other expressions in the clause. In particular, virtually all A-approaches share the assumption that the antecedent of the reciprocal must be the subject of a distributive predication. One free variable is then bound by the plural subject, and the other by the distributive operator. On the PQ-approaches, no free variables are postulated in the lexical representation of each other, and no dependency on a distributive operator is expected. Hence, on the A-approach, reciprocal antecedents are expected to pattern in various ways with distributive subjects, while the PQ-approaches don't lead to that expectation. We will argue that this expectation of the A-approach is unfulfilled. By comparing the reciprocal each other to bound readings of the expression the others, we will provide evidence that the latter expression, in fact, does fulfill these expectations.

The second argument comes from the variety of readings that reciprocal sentences and sentences with the others can give rise to. Even though the A-approach can account for most of the readings, they can do so only by employing technically problematic mechanisms. If we assume that such mechanisms are unavailable, we expect the set of readings to shrink dramatically. The readings we expect corresponds very neatly to the state of affairs we find with the others.

The paper is organized as follows. In the next section we briefly present the PQ- and A-approaches to each other. In Section 3 we summarize the differences between the two strategies that will turn out to be crucial for the rest of the paper. In sections 4 and 5 we present two experiments that test for these predictions. Based on the experiment, we will conclude that the PQ-approach works well for each other, while the A-approach works better for the others but fails to account for each other.

\section{Two research strategies on reciprocity}

\subsection{The $P Q$-approach to reciprocals}

According to the PQ-approach, a reciprocal expression is a type $\langle 1,2\rangle$ polyadic quantifier, i.e. it maps a set and a binary relation to a truth value. Intuitively, the set argument of the reciprocal is its antecedent and the binary relation is provided by a transitive verb, or, more generally, some expression of type eet. The account presented in Dalrymple et al. (1998) derives the various readings of reciprocals by applying operations to the reciprocal relation $R$, such as transitive and symmetric closure. They devise a system of six different readings for each other and postulate their Strongest Meaning Hypothesis to regulate which of these readings a reciprocal gives rise to in any given sentence. For reasons of space we will not discuss the details of their approach here. Instead, we move to a more recent analysis of reciprocals as polyadic quantifiers that achieves similar results in a simpler way. 
In recent work, Winter and Sabato suggest that we can derive the variety of readings without adhering to the massive ambiguity that Dalrymple et al. (1998) need to assume (see Winter 2001, Sabato and Winter 2005). Winter (2001) postulates a quantificational restriction $\Theta_{V}$, which, for any expression $V$ of type eet, provides all possible extensions of $V$ compatible with our world knowledge. Now, it suffices to say that the actual extension of $V$ restricted to the reciprocal antecedent is one of the the strongest relations in $\Theta$, disregarding identities. Let $R_{A}$ abbreviate $R \cap A^{2}$, and let $R^{I}$ abbreviate $R \backslash I d$.

$$
[\text { each other }]]=\lambda R \cdot \lambda A .\left(\forall S \in \Theta_{R}\right)\left(R_{A}^{I} \subseteq S_{A}^{I} \rightarrow R_{A}^{I}=S_{A}^{I}\right)
$$

Let us illustrate how this works with a few examples. In (3a), each other applies to the relation like and the set Aaron, Barbara and Cleo. This means that the like relation, restricted to Aaron, Barbara and Cleo, and with the identities in it subtracted, should be one of the strongest relations that world knowledge about liking allows. This is given formally in (4).

(3) a. Aaron, Barbara and Cleo like each other.

b. Aaron, Barbara and Cleo stood on top of each other.

$$
\left(\forall S \in \Theta_{\text {like }}\right)\left(\operatorname{like}_{A}^{I} \subseteq S_{A}^{I} \rightarrow \operatorname{like}_{A}^{I}=S_{A}^{I}\right)
$$

World knowledge places no constraints on how many persons one may like, or how many one may be liked by. So the strongest denotation we could have in this case is the full cartesian product of the set in question, minus identities. In other words, (4) is true if each of Aaron, Barbara and Cleo likes each of the other ones. On the other hand, the stand on top of relation (SOT) in(3b) is restricted by world knowledge. It cannot denote the cartesian product of our set $\{$ Aaron, Barbara, Cleo $\}$, for example. The strongest relations in $\Theta_{\text {SOT }}$ are strict linear orders.

$$
\left(\forall S \in \Theta_{S O T}\left(S O T_{A}^{I} \subseteq S_{A}^{I} \rightarrow S O T_{A}^{I}=S_{A}^{I}\right)\right.
$$

Finally, Sabato and Winter (2005) can also explain why sentences like (6) are accepted not only in a scenario in which each telephone pole is 500 feet from all the other telephone poles but also in weaker ones. For example, if the telephone poles are in a line and only each pair of neighbouring poles is at 500 feet distance, the sentence is judged true. Under Sabato and Winter's account, this is so because given our world knowledge, we know that telephone poles are constructed in lines, and therefore we expect the relation being 500 feet from to hold only between pairs neighbouring on the line.

The telephone poles are 500 feet from each other.

To sum up, the PQ-approach to reciprocals can capture the semantics of each other and deal with various readings that reciprocal sentences permit simply by manipulating the relation that is the argument of each other. 


\subsection{The A-approach}

There is another long tradition of analyzing each other as a pronominal DP. Probably the best known approach that adheres to this viewpoint is Heim et al. (1991a), and Heim et al. (1991b) but the same position has been considered before (Fiengo and Lasnik 1973) and supplemented with more detail throughout the late nineties (Schwarzschild 1996, Sauerland 1998, Sternefeld 1998, Beck 2001). Here, we consider Beck's account of each other, for its simplicity and empirical coverage.

In Beck's account, each other is treated as a plural definite, with two free variables, viz. the range argument and the contrast argument (see (7)). $z$ and $y$ are the range argument and the contrast argument, respectively, and $\sigma$ is Link's maximality operator, marking definiteness. ${ }^{1}$

$$
\sigma x\left(x \leq z_{\text {range }} \wedge \neg x \circ y_{\text {contrast }}\right)
$$

(7) denotes the maximal individual which is part of $z_{\text {range }}$ (the range argument) and does not overlap with the individual $y_{\text {contrast }}$ (the contrast argument). To understand the meaning of (7) we need to see what binds these two arguments. Beck (2001) follows much research on plurality and adds two operators to the inventory of the formal language, $*$ and $* *$, to capture distributive and co-distributive (cumulative) readings. There are various definitions of the two operators. Beck herself follows Schwarzschild (1996) and assumes that the operators are restricted by covers. For the purposes of this paper we can work with much simpler versions, defined here (Krifka 1986):

$$
\begin{array}{ll}
\text { a. } & * P(x)=1 \text { iff } \mathrm{P}(\mathrm{x})=1 \text { or } \\
& (\exists u, v)(x=u \oplus v \& * P(u) \& * P(v)) \\
\text { b. } \quad * * R(x)(y)=1 \text { iff } \mathrm{R}(\mathrm{y})(\mathrm{x}) \text { or } \\
& \left(\exists x_{1} x_{2} y_{1} y_{2}\right)\left(x=x_{1} \oplus x_{2} \& y=y_{1} \oplus y_{2} \& * * R\left(y_{1}\right)\left(x_{1}\right) \& * * R\left(y_{2}\right)\left(x_{2}\right)\right)
\end{array}
$$

The first operator captures the reading of (9a) according to which each boy weighs 80 kilos, by applying $*$ to the predicate as shown in $(9 \mathrm{c})$.

$$
\begin{aligned}
& \text { a. John, Bill and Jack weigh } 80 \text { kilos. } \\
& \text { b. [John, Bill and Jack }] \in * \lambda x . x \text { weigh } 80 \text { kilos }
\end{aligned}
$$

The second operator does its work in capturing reading (10b) of the sentence (10a). Again, this is achieved by applying ** to the relation as shown in (10c).
a. John and Bill ate two pizzas.
b. John ate one pizza and Bill ate one pizza.
c. $\quad[$ John and Bill $][2$ pizzas $] \in * * \lambda x y \cdot x$ ate $y$

\footnotetext{
${ }^{1} \sigma x . P x$ picks the maximal $x$ for which the proposition $P x$ holds. Formally: $\sigma x . P x=\imath x . P x \wedge$ $(\forall y)(P y \rightarrow y \leq x)$. We follow Link (1983) and assume that singular and plural individuals are members of the same domain, $e$, which is a complete join semilattice, closed under $\oplus . a \oplus b$ can be read as 'sum of $a$ and $b$ '. $a \leq b$ can be read as 'individual $a$ is a part of individual $b$ '.
} 
With this simple theory of plural predication in mind, let us go back to the semantics of reciprocity. To obtain the right semantics for each other (7), we need to state the conditions on binding of the two free variables. We can illustrate this with the example (11a). $y_{\text {contrast }}$ is bound by the lambda operator in the scope of $*$ that corresponds to the subject. $z_{\text {range }}$ is bound by the plural subject itself. ${ }^{2}$ Given all this, we get the representation in (11b). This representation will be true in (11c), which is what we want.

$$
\begin{aligned}
& \text { a. Aaron, Barbara and Cleo talked to each other. } \\
& \text { b. }[a \oplus b \oplus c]_{z} \in * \lambda y \cdot y \text { talked to } \sigma x\left(x \leq z_{\text {range }} \wedge \neg x \circ y_{\text {contrast }}\right) \\
& \text { c. } \quad\left(\forall x, y \leq_{a} a \oplus b \oplus c\right)(\operatorname{talk}(x, y))
\end{aligned}
$$

Beck makes use of the ** operator to account for some of the weaker readings that reciprocal sentences permit. We mentioned two examples of weaker readings in Section 2.1, and they are both repeated here.

(12) a. John and Bill stood on top of each other.

b. The telephone poles are 500 feet from each other.

Let us start with (12b) which can be dealt with by employing the $* *$ operator. As it turns out, the actual implementation is far from trivial, though. The $* *$ operator applies to relations. In example (12b), one might think that the relation is $[\lambda x y . x$ is 500 feet from $y]$. But this will not work. Consider:

$$
\text { [telephone poles }]_{z} \sigma x(x \leq z \wedge \neg x \circ y) * * \lambda u v . u 500 \text { feet from } v
$$

The problem with (13) is the contrast argument $y$ inside each other. It ends up unbound because it is not within the scope of $* *$, and, hence, outside the scope of the lambda below it that corresponds to the subject of the relation. The solution that Beck suggests is that only part of the meaning of each other, namely, the range argument, moves in front of the $* *$ operator. Thus, we have the following:

$$
\text { [telephone poles] }]_{z} z * * \lambda u v . u 500 \text { feet from } \sigma x(x \leq v \wedge \neg x \circ u)
$$

Given the definition of $* *$ above, the cumulated relation is true of $x$ and $y$ if $x$ and $y$ have subparts for which the relation holds. One possibility is to take all plural individiduals consisting of two adjacent poles as subparts of $z$, and singular individuals that are part of thereof to be subparts of [telephone poles]. Then, (14) means roughly 'in the line of telephone poles, adjacent poles are 500 feet from each other'. This correctly captures the relevant reading of (12b).

Even though employing $* *$ might work for examples like (12b) they cannot account for still weaker readings, represented by (12a). If we apply the $* *$ operator we get the following:

\footnotetext{
${ }^{2}$ Beck suggests that this could be obtained by letting the plural subject undergo $\mathrm{QR}$ and then having $z_{\text {range }}$ bound by the lambda that such QR creates. For ease of exposition, she omits this last step from her derivations, and we will follow her practice here.
} 


$$
\text { [John and Bill] }]_{z} z * \lambda u v \cdot u \text { stood on top of } \sigma x(x \leq v \wedge \neg x \circ u)
$$

To make (15) true we need to find subparts of John and Bill which are the subject of the relation stand on top of. The only posssibility is to take the individuals as subparts. But that would mean that John, as well as Bill, must stand on top of the other person. Hence, Beck can't deal with sentences like (12b), as she admits. To be fair, we should point out that the PQ approach also runs into trouble with such readings. In this case, the problem is one of over-generation. The PQ approach can't explain why sentences like the following only have contradictory readings, since the reasoning from world knowledge should run exactly parallel to that for (15). We leave it to the reader to work out what readings the PQ approach would expect for (16a-c).

a. \# The four men are each other's fathers.

b. \# Ron, Tom, and John are taller than each other.

\section{Predictions of the two strategies}

In this section we will show that, by comparing each other to the expression the others, we can extract testable predictions that the PQ- and A-approaches make concerning differences and similarities between the two expressions.

\subsection{Range of antecedents}

In Beck's approach, the various readings are derived by manipulating $*$ and $* *$ operators. In fact, reciprocal sentences must always have $*$ or $* *$ operators, otherwise the contrast argument of the reciprocal would not be bound. In PQ-approaches, there is no need for $*$ operators to derive reciprocal sentences. ${ }^{3}$

What we have just said about Beck's approach is true virtually of every A-approach. It is telling that one A-approach which derives reciprocal sentences without the use of $*$ or $* *$ operators (Heim et al. 1991a) fails in other respects. Heim et al. (1991a) assume that each other can be decomposed into each and other. In their account other is interpreted similarly as Beck's each other (i.e. as a plural definite with two free variables, the contrast and range argument) and each is interpreted as the floating quantifier each that adjoins to the antecedent at the LF and binds the contrast argument. While this account can capture reciprocal sentences without $*$ or $* *$ operators, it cannot derive the full range of readings that reciprocal sentences permit. Furthermore, it fails to account for some readings of sentences in which more than one reciprocal appears (as discussed by Williams 1991 and Heim et al. 1991b).

Both $*$ and $* *$ operators are used in the theories of plural predication to derive distributive and co-distributive (cumulative) readings, respectively. It has

\footnotetext{
${ }^{3}$ In fact, the $*$ operator that distributes down to singularities must not apply to the antecedent of each other in PQ-approaches.
} 
been known for some time in the psycholinguistic literature that distributive readings are less acceptable with definite plural subjects than with quantified subjects (Brooks and Braine 1996, Kaup et al. 2002). Thus, the difference between PQand A-approaches is testable. Under A-approaches, we expect that this difference between definite plural and quantified subjects should hold for strongly reciprocal sentences. In other words, reciprocals should be less acceptable with simple definite plural antecedents than with quantified antecedents. No such expectation arises on PQ-approaches. Furthermore, if we would keep Beck's anaphoric semantics for the others, we would expect antecedents of bound readings of the others also to behave as subjects of distributed predicates. We designed two experiments to test these predictions. In Experiment 1 we test whether the others behave as Beck's semantics makes us expect (Section 4). In Experiment 2 we are going to see how each other behaves with respect to the type of antecedents (Section 5). To sum up, if we find that sentences with the others are degraded with definite plurals as antecedents, as compared to quantified antecedents, this would support Beck's semantics for the others. If we have the same result for each other, this would again support Beck's semantics, and would be problematic for PQ-approaches. On the other hand, if reciprocals are fully accepted with both quantified antecedents and definite plural subjects, this would be an argument against Beck's semantics for each other, and for PQ-approaches.

\subsection{Range of readings}

The two approaches differ with respect to how they derive weaker readings of sentences like (17) repeated from above.

(17) The telephone poles are 500 feet from each other.

In Beck's approach this is done by assuming the presence of the ** operator and, crucially, QR of the range argument of each other, as discussed. Requiring QR of the range argument seems a strange operation, for various reasons: First, it would require $\mathrm{QR}$ out of a definite island; secondly it would require $\mathrm{QR}$ of a variable; and finally, it would require QR of a proper sub-part of the semantic representation of an idiom. While there may be reasons to assume that some of these things are possible, we think it is preferable to pursue a more restrictive theory of the syntax-semantics interface, where such operations are disallowed.

If we suppose that such QR is not possible, and that Beck's semantics should be assigned to the others, we would expect that this expression should lack the weak construals that characterize each other. The PQ approach to each other was designed to capture its range of readings. Hence, assuming that the others is a definite plural and that each other is a PQ, we expect a contrast between the two in terms of their ability to support weak readings. We designed one experiment to test these predictions (Experiment 2, Section 5). 


\section{Experiment 1}

In this experiment, we tested the relative preferences native speakers of Dutch have for which types of noun phrases (distributive universals, antiadditives, definite plurals, conjunctions of names) could serve as antecedents for bound readings of a variety of expressions, such as een ander ('a different'), een verschillend ('a different'), de anderen ('the others'), and distributive predicates such as loose a tooth. For the purposes of the present paper, the comparison between bound readings of de anderen ('the others) and subjects of distributive predication is of prime interest.

\subsection{Method}

We designed a web-based experiment in which approximately 1150 native speakers of Dutch participated. The experiment had six different lists of test items, and each participant was sent to one of those lists. Within each list, there were 24 test items, and 8 fillers with around 185 speakers completing each list. The test items and fillers were presented with a background scenario intended to strongly favor certain readings of the relevant expressions. Each list had 4 different scenarios, and the test items were presented in random order. The following is an example of a scenario:

Scenario 1. De matrozen Jip, Jaap en Joop kwamen terecht op een onbewoond eiland. Na een tijdje kregen ze ruzie en gingen ze ieder hun eigen weg. Jip ging in het scheepswrak wonen, Jaap nam zijn intrek in een grot, en Joop vond een verlaten hut. Ieder van hen dacht dat zijn nieuwe behuizing de slechste was. Hierdoor werden ze jaloers op elkaar.

The sailors Jip, Jaap, and Joop were stranded on an uninhabited island. After a while, they started quarreling, and went their separate ways. Jip went to live in the shipwreck, Jaap moved into a cave, and Joop found himself an abandoned hut. Each of them thought his own dwelling was the worst one. Therefore they were jealous of each other.

The speakers were presented with a sentence and asked whether they can say it, given the scenario. They had six buttons to choose from, and they were marked as shown in (18).

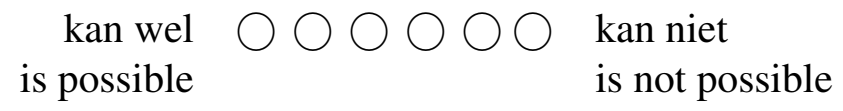

As we said above, for the purpose of this paper, it is only important to see how bound readings of the others were accepted with different antecedents, and how distributive predication was accepted with different plural subjects. The list of these test items for Scenario 1 is given here with coding we use throughout:

(19) a. Elke matroos was jaloers op de anderen. (coding: elk-de anderen) Each sailor was jealous of the others

b. Ieder matroos was jaloers op de anderen. (coding: ieder-de anderen) Every sailor was jealous of the others 
c. Alle matrozen waren jaloers op de anderen. (alle-de anderen) All sailors were jealous of the others

d. De matrozen vonden een onderkomen. (coding: de-de anderen) the sailors found a dwelling

e. Jip, Jaap, en Joop waren jaloers op de anderen. (en-de anderen) Jip, Jaap, and Joop were jealous of the others

f. Ieder matroos vond een onderkomen. (coding: ieder-dist) every sailor found a dwelling

g. De matrozen vonden een onderkomen. (coding: de-dist) the sailors found a dwelling

h. Jip, Jaap, en Joop vonden een onderkomen. (coding: en-dist) Jip, Jaap, and Joop found a dwelling

\subsection{Results of Experiment 1}

For each test sentence, we got a distribution of judgments which was strongly nonnormal: the extreme values 1 and 6 were selected much more often than middle values. ${ }^{4}$ Therefore, we could not rely on parametric statistical tests. We used two non-parametric test, namely Wilkoxon's rank sum and signed rank tests, and also logistic regression to overcome this problem. For the same reason, we don't report mean scores for the various sentences, since the bimodality of the score distributions would render the means misleading.

With rank sum tests, one ranks all the individual scores obtained in two independent groups for a variable, and tests whether the sum of ranks is significantly different between the two groups. If the sum of ranks in the first group is significantly lower than the sum of ranks for the second, then the first group had a higher acceptance for the test sentences than the second group.

With a Wilcoxon's signed rank test, one tests the same group of speakers whether they liked one sentence better than another. One ranks their judgments separately for the two cases and checks for each speaker, whether her rank in one case is higher/lower than in the other. If the number of speakers who went down in rank from the first to the second case is significantly larger than the number of speakers who went up in rank, then the first sentence is judged worse than the second.

The signed rank test has stronger statistical power than the rank sum test, so whenever possible, we use signed rank tests. We have never used this difference in statistical power to support our conclusion, however: In no case where we are making a comparison between two cases have we shown lack of significance with the weak test and presence of significance with the strong test.

\footnotetext{
${ }^{4}$ We suspect that the reason why the speakers tended to select extreme values 1 or 6 was that we had used relatively "mild" labels for the extreme values. Had we used labels like "perfect" and "completely impossible" instead, the results might have been different. We think this is a general problem with the use of fixed scales in questionnaires.
} 
4.2.1. En and de are worse subjects of distributive predicates than the quantified noun phrases

We compared speaker's reactions to three types of subjects of distributive predicates, ieder ('every') (19f), de NP (definite plural) (19g) and en NP (coordinated subject) (19h). In Table 1, we see that en NP/de NP were both worse than ieder with distributive predicates. ( $X>Y$ means that $X$ is judged significantly worse than $Y . X=Y$ is used when $X$ and $Y$ were not significantly different from one another.) We also give bar diagrams for the judgments in Figure 1. The significant difference between the two types of antecedents was found across scenarios, as well as within scenarios.
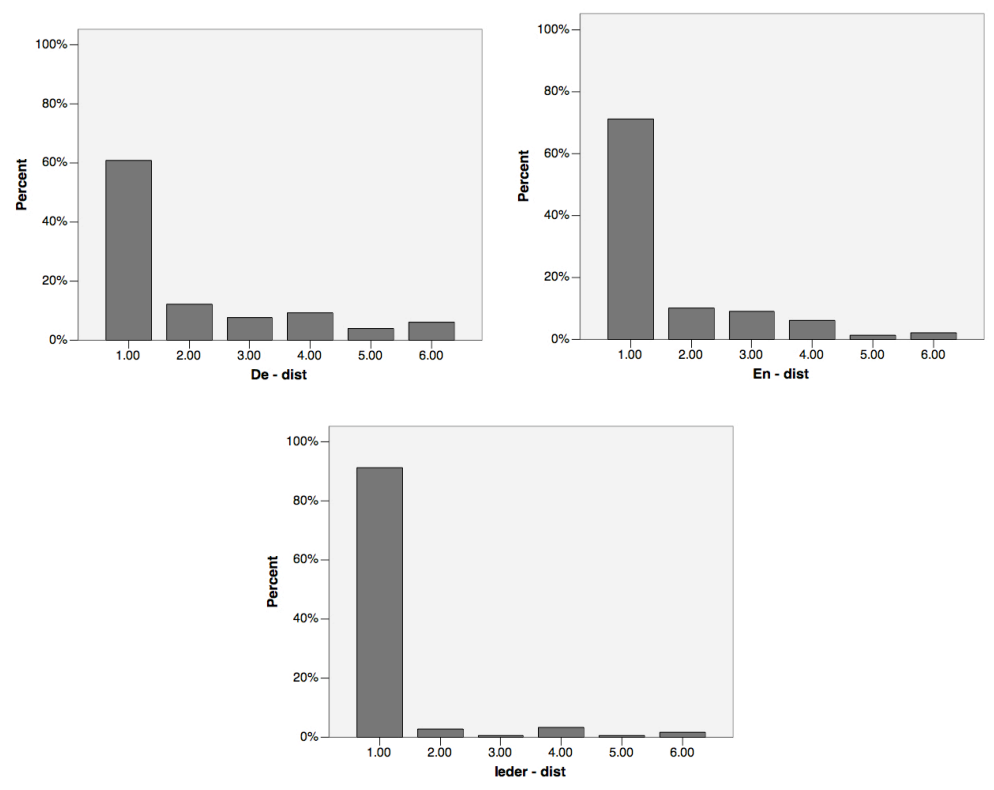

Figure 1: Percentage of different judgments for DIST with various subjects

Table 1: Rank-sum test comparing subjects of distributive predicates

\begin{tabular}{ll||r|l|l} 
& & Mann-Whitney's $U$ & effect size & sig. \\
\hline \hline de & $>$ ieder & 47054.00 & $r=-.36$ & $p<.0005$ \\
\hline en & $>$ ieder & 53118.50 & $r=-.25$ & $p<.0005$
\end{tabular}

4.2.2. En and de are worse antecedents for de anderen than the quantified antecedents

In Table 2, we compare how sentences with de anderen ('the others') were accepted depending on whether the antecedent of de anderen was de NP (19d) and en NP (19e), or the quantified noun phrases (19a-19c). As we can see, definite plurals and coordinations are judged significantly worse than than quantified noun phrases. 
Table 2: Rank-sum test comparing various antecedents of de anderen

\begin{tabular}{cl||r|l|l} 
& & Mann-Whitney's $U$ & effect size & sig. \\
\hline \hline de & $>$ elk & 111394.00 & $r=-.25$ & $p<.0005$ \\
& $>$ ieder & 113037.00 & $r=-.24$ & $p<.0005$ \\
& $>$ alle & 29946.00 & $r=.06$ & $p<.05$ \\
\hline en & $>$ elk & 20002.00 & $r=-.35$ & $p<.0005$ \\
& $>$ ieder & 17876.00 & $r=-.41$ & $p<.0005$ \\
& $>$ alle & 45447.50. & $r=-.28$ & $p<.0005$
\end{tabular}

The difference between definite plurals and coordinations, on the one hand, and quantified NPs, on the other hand, can be also observed from bar diagrams. Figure 2 gives bar diagrams for the former. Figure 3 gives us bar diagrams of judgments with quantified NPs.
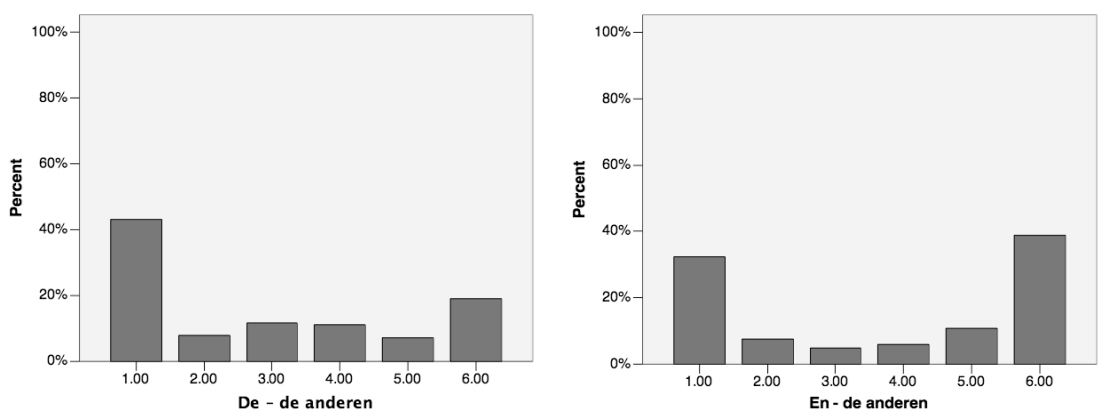

Figure 2: Percentage of judgments en/de anteceding de anderen

Table 2, shows that de and en are both significantly worse than ieder and $e l k$, and that the effect size is larger for $e n$ than it is for $d e$.

We also compared the various quantificational antecedents of de anderen to each other. Ieder and elk are not significantly different, but these are both significantly better than alle.

Table 3: Signed rank tests comparing various quantificational antecedents of de anderen

\begin{tabular}{ll||r|r|l} 
& & $T$ & effect size & sig. \\
\hline \hline elk & = ieder & 11789.50 & -- & $p=.697$ \\
& $<$ alle & 7602.00 & $r=.25$ & $p<.0005$ \\
\hline Ieder & $<$ alle & 5094.00 & $r=.39$ & $p<.0005$ \\
\hline
\end{tabular}

Finally, we tested whether the difference between scenarios had a significant effect on the judgments. The results for the other antecedent types are given in Table 4. We see that, in three cases, there are significant differences between the scenarios, concerning how a particular antecedent was judged. We would like to point out, however, that, although these effects of the scenarios are significant, they 

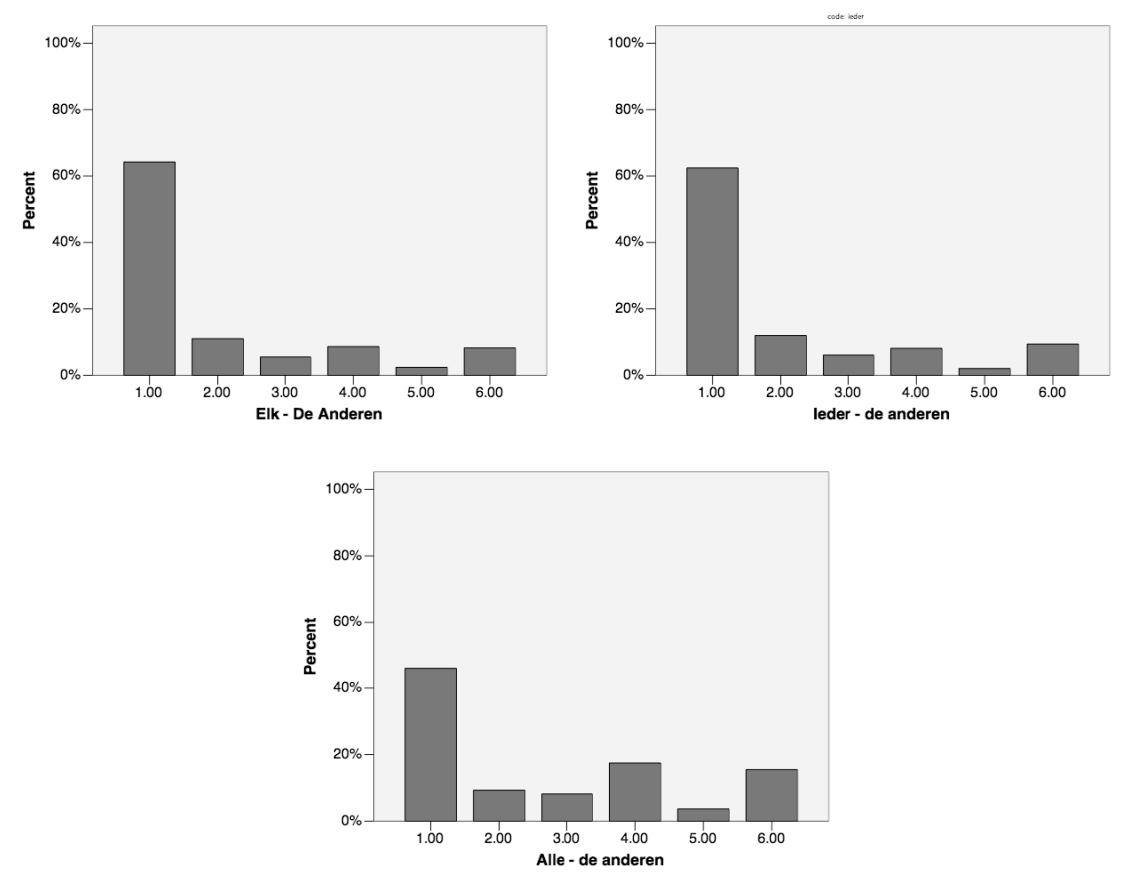

Figure 3: Quantificational antecedents of de anderen

Table 4: Testing influence of different scenarios on availability of bound de anderen for various antecedents.

\begin{tabular}{ll||r|l|l} 
& & Mann-Whitney's $U$ & effect size & sig. \\
\hline \hline elk & Sc1 $<$ Sc2 & 60407.00 & $r=-.08$ & $p=.03$ \\
\hline ieder & Sc1 $=$ Sc2 & 62272.50 & -- & $p=.23$ \\
\hline de & Sc2=Sc3 & 68057.50 & -- & $p=.73$ \\
\hline en & Sc1 $>$ Sc3 & 14350.00 & $r=-.17$ & $p=.001$ \\
& Sc2 $<$ Sc3 & 14879.50 & $r=-.14$ & $p=.006$
\end{tabular}

did not influence our results. For example, the coordination en was judged better in scenario 2 than it was in scenario 3. Similarly, elk was judged better in scenario 1 than it was in scenario 2. Regardless of which scenario we would choose for comparison, en comes out as a less good antecedent for de anderen than elk. Parallel remarks can be made concerning all the results we have reported above.

\subsubsection{De anderen implies DIST}

We also tested whether one can infer with reasonable confidence from a speaker's acceptance of sentences of the form [en/de... de anderen] that this speaker will also accept sentences of the form [en/de... DIST VP]. With logistic regression one can estimate the likelihood of obtaining an outcome $x$ for a categorical (i.e. "yes/no") variable, such as whether a sentence is judged possible or impossible (the dependent variable), given some other information (the predictors). To be able to use this 
on our data, we transformed the judgment variable into a categorical one, i.e. we mapped all judgments in the interval $[1,3]$ to 1 and the ones in the interval $[4,6]$ to 0 . Given that most judgments were clustered at the extreme values this move would lose very little information.

We tested whether speakers' judgments for en/de with distributive predication could serve as a predictor for what their judgments would be for en/de as antecedents for de anderen. The results are reported in Table 5. For example, 92\% of the speakers who accepted de anderen bound by conjunctions of names would also accept plain distributivity with such noun phrases. 56\% of those who did not accept de anderen bound by conjunctions still accepted conjunctions as distributive subjects. That is, if a speaker accepted [Jan, Wim, en Kees ... de anderen], we can be fairly certain that she also accepted [jan, Wim, en Kees DIST VP]. If she rejected the first of the two, we are left guessing about what she said about the second.

Table 5: Logistic regression testing En/De-DIST as a predictor for En/De-deAnd.

\begin{tabular}{l||l|l|l} 
& $B$ (St.Err.) & $\exp (b)[95 \%$ C.I. $]$ & model $\chi^{2}(1)$ \\
\hline \hline EnDeAnd $\rightarrow$ EnDist & $-2.212^{* *}(.431)$ & $.110[.047, .255]$ & $33.415^{* *}$ \\
DeDeAnd $\rightarrow$ DeDist & $-1.307^{*}(.390)$ & $.271[.126, .581]$ & 11.719 \\
${ }^{*} p=.001, \quad{ }^{* *} p<.0005$ & & &
\end{tabular}

\subsection{Discussion}

As has been already noted in the psycholinguistic literature, distributive predicates are judged more acceptable with quantified DPs than with definite plurals (Brooks and Braine 1996, Kaup et al. 2002). Our experiment confirms these results, and adds to those that coordination is as bad as definite plurals, as we have seen in Section 4.2.1. Secondly, the results in Section 4.2.2 show that similarly, quantified DPs are better antecedents of the others than definite plurals or coordinations. We take it to strongly suggest that the insertion of the $*$ operator to derive distributive readings is marginal and degraded with definite plurals or coordinations. Since we observe degradation with the same range of antecedents in case of bound the others we conclude that the others requires insertion of the $*$ operator. This is expected if the others comes with the semantics that Beck proposed for each other (Section 3).

\section{Experiment 2}

The second experiment tested whether the type of antecedent of each other influences acceptance of reciprocal sentences, in the same way as the antecedent of the others does. Second, the experiment tested which readings are accepted with each other and bound the others. Of the many readings that are discussed in the semantic literature (Langendoen 1977, Dalrymple et al. 1998, Beck 2001, Sabato and Winter 2005: a.o.) we focused only on three readings (already discussed above). 
The strongest one, in which the relation between the members of the antecedent set $A$ equals $A^{2} \backslash I d$. It is exemplified by (20a) and can be paraphrased as each of Aaron, Barbara and Cleo like all the others. The second relation is exemplified by (20b), in the context in which the telephone poles are in a line. It represents cases in which A-approaches have to asssume that the $* *$ operator applies to the relation (see Sections 2.2 and 3). The third relation is exemplified by (20c), in the context of one column of boxes. It represents the weak readings which cannot be captured in Beck's system. Following Dalrymple et al. (1998) we call the first relation SR (strong reciprocity), the second one IR (intermediate reciprocity), the third one IAR (intermediate alternative reciprocity).

(20) a. Aaron, Barbara and Cleo like each other. (SR)

b. The telephone poles are 500 feet from each other. (IR)

c. The boxes are stacked on top of each other. (IAR)

\subsection{Method}

We designed a web-based questionnaire in which 40 undergraduate students of linguistics from University College of London participated. Before the experiment, each participant was instructed that she "will be presented with 28 situations consisting of a picture and a sentence describing it" and that she "will be asked whether the sentence is a true statement about the picture" and should bear in mind that "there is no "correct" or "incorrect" answer in any of the situations". Each test item consisted of a picture under which the test sentence has been presented, as shown in Figure 4. The participant had to click on the button to choose between the answer "true" or "false", and could optionally fill in her commentary before moving to the next test item.

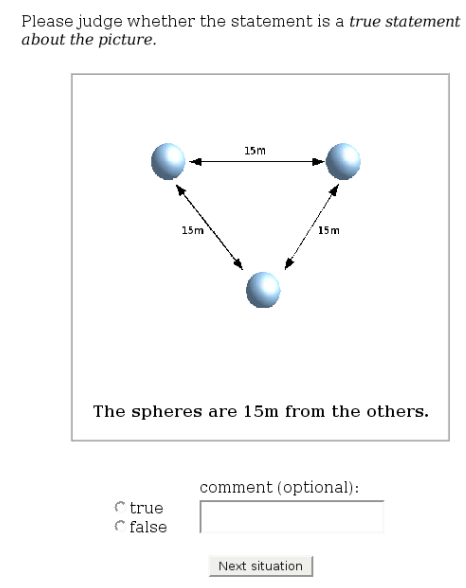

Figure 4: Example of a test item

The questionnaire had two lists, and each participant was sent to one of them. List 1 differed from List 2 in the type of the antecedent for each other and the 
Table 6: All NP and The NP: Mean proportions of sentences judged as true in total

\begin{tabular}{l||ll|l|l} 
& antecedent $=$ all NP & antecedent $=$ the NP & sig. \\
\hline all test items & .4831818 & $\approx .5547059$ & $\mathrm{p}=.16$ \\
\hline each other & .5509091 & $<.7794118$ & $\mathrm{p}=.001$ \\
the others & .3647059 & $\approx .3317647$ & $\mathrm{p}=.687$
\end{tabular}

others. List 1 consisted of test items in which the antecedent was a quantifier headed by all while list 2 consisted of test items in which the antecedent was a definite plural. In total, each picture was tested for 4 different sentences. For example, the picture in Figure 4 has been used as the background for testing truth value judgments in the following quadruple (where (21a) and (21b) appeared in List 1, while (21c) and (21d) appeared in List 2):

(21) a. All the spheres are $15 \mathrm{~m}$ from each other.

b. All the spheres are $15 \mathrm{~m}$ from the others.

c. The spheres are $15 \mathrm{~m}$ from each other.

d. The spheres are $15 \mathrm{~m}$ from the others.

Within each list, there were 14 test items and 10 fillers, presented in randomized order. Of the 14 test items, 4 tested SR, 6 tested IR, and 4 tested IAR.

\subsection{Results of Experiment 2}

\subsubsection{Comparing the antecedents all NP and the NP}

Table 6 shows the mean proportion of sentences judged as true within the scenario. To test whether the mean proportion differed depending on the type of antecedent we applied independent t-test which compares two means of independent samples. When non-differentiated according to the type of reading and the presence of each other or bound the others, the sentences with all NP were less frequently judged as true than the $N P$, even though the result was not significant $(\mathrm{p}=.16)$. For the sentences in which only each other was used, the antecedent all NP significantly decreased the acceptability $(\mathrm{p}=.001, \mathrm{t}=-3.47, \mathrm{df}=35.56)$. There was no significant difference between the two antecedents in case of bound the others.

When we further differentiate test items according to the type of reading, we get the following results (Table 7). First, each other is less accepted in SR with definite plurals than with quantified all the NP. The same holds for the others. How-

ever, this result is confounding because one of the test items in the questionnaire could only be accepted under distributive readings. The crucial example is given here in (22), with the picture that formed the relevant context (Figure 5). As you can see the indefinite a line must be distributed over, otherwise the sentence is false.

(22) The boxes are connected to each other by a line. 


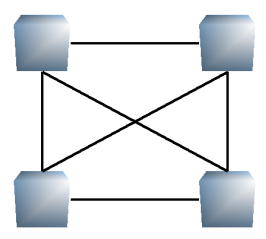

Figure 5: A picture to (22)

Table 7: All NP and The NP: Mean proportions of sentences judged as true for different readings

\begin{tabular}{l||lll|l} 
& antecedent $=$ all NP & & antecedent $=$ the NP & sig. \\
\hline each other in $\mathrm{SR}$ & .98 & $>.72$ & $\mathrm{p}=.0007$ \\
each other in $\mathrm{SR}_{1}$ & 1.0 & $=1.0$ & - \\
each other in $\mathrm{IR}$ & .62 & $<0.88$ & $\mathrm{p}=.01$ \\
each other in $\mathrm{IAR}$ & .52 & $<.88$ & $\mathrm{p}=.004$ \\
\hline the others in $\mathrm{SR}$ & .84 & $>.44$ & $\mathrm{p}=.0009$ \\
the others in $\mathrm{SR}_{1}$ & .81 & $>.52$ & $\mathrm{p}=.05$ \\
the others in $\mathrm{IR}$ & .38 & $\approx 0.29$ & $\mathrm{p}=.4223$ \\
the other in $\mathrm{IAR}$ & .04 & $\approx .25$ & $\mathrm{p}=.06$
\end{tabular}

When we put aside this test item, we get the results for Strong Reciprocity as reported in $\mathrm{SR}_{1}$. As one can see, now each other is fully accepted in Strong Reciprocity no matter which antecedent is chosen. The sentences with the others are judged as true more frequently when the antecedent is all NP than when the antecedent is a definite plural, and the difference is just significant $(\mathrm{p}=0.05, \mathrm{t}=$ 2.02, df = 33.59). Furthermore, all NP is dispreferred as the antecedent for each other in Intermediate Reciprocity $(\mathrm{p}=.01, \mathrm{t}=-2.65, \mathrm{df}=35.63)$ and Intermediate alternative reciprocity $(\mathrm{p}=0.004, \mathrm{t}=-3.15, \mathrm{df}=31.03)$. For the others the difference between the type of antecedent is non-significant in case of Intermediate Reciprocity and Intermediate Alternative Reciprocity.

\subsubsection{Range of readings with each other and bound the others}

To compare which readings were accepted/rejected with each other and bound the others, we wanted to minimize the effect of the antecedent. Since we knew from Experiment 1 that bound de anderen is less accepted when the antecedent is a definite plural than when the antecedent is a quantifier headed by all (see Section 4.2.2) and this has also been confirmed in the first part of our Experiment 2, we decided to make use only of the data in which all NP is the antecedent. Table 8 shows the mean proportion of sentences judged as true for each type of reading. In Strong Reciprocity, the difference between each other and the others has been very close to significant $(\mathrm{p}=.06)$. In Intermediate Reciprocity, the difference was significant $(\mathrm{p}=0.006, \mathrm{t}=3.04, \mathrm{df}=21)$. In Intermediate Alternative Reciprocity, the difference was highly significant $(\mathrm{p}=0.0001, \mathrm{t}=4.71$, $\mathrm{df}=21)$. 
Table 8: each other and the others: Mean proportions of sentences judged as true for different readings

\begin{tabular}{l||lll|l} 
& each other & the others & sig. \\
\hline strong reciprocity & .98 & $\approx .84$ & $\mathrm{p}=.06$ \\
intermediate reciprocity & .62 & $>.38$ & $\mathrm{p}=.006$ \\
intermediate alternative reciprocity & .52 & $>.04$ & $\mathrm{p}=.0001$
\end{tabular}

\subsection{Discussion}

In Experiment 1 we established that bound de anderen 'the others' requires distributivity, either supplied through distributive operator, or through distributive quantifiers. When we want to see how each other behaves we must concentrate only on one type of reading, SR (see Table 7). The reason is that with other readings there is a confounding factor, namely, some speakers do not accept IR or IAR when the antecedent of each other is all NP. Moreover, looking at SR we must ignore one test item in which distributivity is independently needed, because of the presence of an indefinite that must be distributed over (22). Thus, we end up with $\mathrm{SR}_{1}$, where each other is fully accepted regardless of the antecedent. This shows that each other, unlike bound the others does not need the $*$ operator to be interpreted. This conclusion is compatible with PQ-approaches to each other while suggests that Beck's analysis in the line of the A-approach should be reserved only to the others. ${ }^{5}$

Secondly, Table 8 shows us that the others was significantly less accepted than each other with weaker readings. We can make sense of this if we assume PQ-approaches to each other and restrict the A-approach to the others. To account for IR Beck needs to assume that a QR of a variable takes place, something that runs into various problems which we discussed in Section 3. If we just accept that this QR is not possible we do predict low acceptance rate of IR for the others. Under Beck's account, we also expect that the others should not be accepted in IAR readings because, as Beck herself notes, these readings are not derivable in her account (see also our discussion in Section 2.2).

\section{Conclusion}

We have presented two predictions that are made by A-approaches and that are unfulfilled when tested on reciprocals. By comparison, the same predictions hold for bound the others. Rather than adding extra stipulations to Beck's account to explain the behavior of each other we take these results to mean that her account is correct, but should be restricted to expressions like the others. This leaves the PQ-approach as better suited to handle the properties of each other.

\footnotetext{
${ }^{5}$ Notice, incidentally, that in Experiment 2 we confirm the results from Experiment 1 that the all $N P$ is a better antecedent of the others than the NP.
} 


\section{References}

Beck, Sigrid: 2001, 'Reciprocals are definites', Natural language semantics 9, 69138.

Brooks, Patricia J. and Martin D.S. Braine: 1996, 'What do children know about the universal quantifiers all and each?', Cognition 60, 235-268.

Dalrymple, Mary, Makoto Kanazawa, Yookyung Kim, Sam Mchombo, and Stanley Peters: 1998, 'Reciprocal expressions and the concept of reciprocity', Linguistics and Philosophy 21, 159-210.

Fiengo, Robert and Howard Lasnik: 1973, 'The logical structure of Reciprocal sentences in English', Foundations of language 9, 447-468.

Heim, Irene, Howard Lasnik, and Robert May: 1991a, 'Reciprocity and plurality', Linguistic Inquiry 22, 63-192.

Heim, Irene, Howard Lasnik, and Robert May: 1991b, 'Reply: on 'reciprocal scope", Linguistic Inquiry 22, 173-192.

Kaup, Barbara, Stephanie Kelter, and Christopher Habel: 2002, 'Representing referents of plural expressions and resolving plural anaphors', Language and Cognitive Processes 17, 405-450.

Keenan, Ed: 1992, 'Beyond the Frege boundary', Linguistic Inquiry 15, 199-221.

Krifka, Manfred: 1986, Nominalreferenz un Zeitkonstitution: Zur Semantik von Massentermen, Pluraltermen und Aspektklassen, Doctoral Dissertation, University of Munich.

Langendoen, Terence D.: 1977, 'The logic of reciprocity', Linguistic Inquiry 9, 177-197.

Link, Godehard: 1983, 'The logical analysis of plurals and mass terms: a latticetheoretic approach', in R. Bauerle, C. Schwarze, and A. von Stechow (eds.), Meaning, use, and the interpretation of language. de Gruyter, Berlin.

Sabato, Sivan and Yoad Winter: 2005, 'From semantic restrictions to reciprocal meanigns', in Proceedings of FG-MOL.

Sauerland, Uli: 1998, 'Plurals, derived predicates, and reciprocals', in U. Sauerland and O. Percus (eds.), The interpretive tract - MIT working papers in linguistics 25, 177-204. MIT, Cambridge, Massachusetts.

Schwarzschild, Roger: 1996, Pluralities. Kluwer, Dordrecht.

Sternefeld, Wolfgang: 1998, 'Reciprocity and cumulative predication', Natural language semantics $\mathbf{6}$.

Williams, Edwin: 1991, 'Reciprocal scope', Linguistic Inquiry 22, 159-173.

Winter, Yoad: 2001, 'Plural Predication and the Strongest Meaning Hypothesis', Journal of Semantics 18, 333-365. 